\title{
Postoperative Nausea and Vomiting in Patients Undergoing Total Abdominal Hysterectomy Under Subarachnoid Block: A Randomized Study of Dexamethasone Prophylaxis
}

\author{
Khatiwada S, ${ }^{1}$ Bhattarai B, ${ }^{1}$ Biswas BK, ${ }^{2}$ Pokharel $\mathrm{K},{ }^{1}$ Acharya $\mathrm{R},{ }^{3}$ Singh $\mathrm{SN},{ }^{1}$ Uprety ${ }^{4}$
}

${ }^{1}$ Department of Anaesthesiology and Critical Care, BPKIHS, Dharan, Nepal

${ }^{2}$ Department of Anaesthesiology, NEIGRIHMS, Shillong, India

${ }^{3}$ Department of Otorhinolaryngology and head and neck surgery, Nobel Medical College, Biratnagar, Nepal

${ }^{4}$ Department of Obstetrics and Gynaecology, BPKIHS, Dharan, Nepal

\section{Corresponding Author}

Sindhu Khatiwada

Department of Anaesthesiology and Critical Care, BPKIHS, Dharan, Nepal

Email: drsindhukhatiwada@yahoo.com

\section{Citation}

Khatiwada S, Bhattarai B, Biswas BK, Pokharel K, Acharya $\mathrm{R}$, Singh SN et.al. Postoperative Nausea and Vomiting in Patients Undergoing Total Abdominal Hysterectomy Under Subarachnoid Block: a Randomized Study of Dexamethasone Prophylaxis. Kathmandu Univ Med J 2012;38(2):41-45.

\begin{abstract}
Background

Postoperative nausea and vomiting is a common distressing problem in patients undergoing gynaecological surgery under anaesthesia including central neuraxial blockade, which requires frequent medical interventions.
\end{abstract}

\section{Objectives}

We aimed to find out the antiemetic effect of prophylactic dexamethasone for prevention of postoperative nausea and vomiting in patients undergoing total abdominal hysterectomy under subarachnoid block. Influences of dexamethasone on patient satisfaction and postoperative analgesia were also observed as secondary objectives.

\section{Methods}

This was a prospective, randomized, double blind, placebo controlled study conducted in BPKIHS, a Tertiary care University based hospital from January 2009 to April 2009, for a period of four months. This study involved 80 American Society of Anaesthesiologist Physical Status I\&II patients undergoing total abdominal hysterectomy under subarachnoid block. Patients were divided into two groups of 40 each to receive either $4 \mathrm{mg}$ of dexamethasone (group D) or normal saline (group $\mathrm{N}$ ) in volume of $2 \mathrm{ml}$ intravenously 1 hourr prior to subarachnoid block. Surgery was allowed to start with block height of at least T8 dermatome. Intraoperative and postoperative nausea and vomiting was observed using nausea and vomiting scale every 4 hour for 24 hours.

\section{Results}

Seven (17.4\%) patients in group D and 11 (27.5\%) patients in group $N$ had nausea and vomiting in the intraoperative period $(P=0.284)$. Sixteen (40\%) patients in group $D$ experienced nausea and vomiting in the postoperative period as compared to $27(67.5 \%)$ in group $N(P=0.0136)$. Accordingly, the mean requirement of rescue antiemetic was less in group $D$ compared to Group N ( $P=0.042)$. Further, only 15 $(37.5 \%)$ patients in group $D$ required postoperative supplemental analgesic as compared to $23(57.5 \%)$ in group N ( $P=0.058)$. After 24 hrs of surgery, $26(65 \%)$ patients expressed satisfaction in group $\mathrm{D}$ as compared to $16(40.0 \%)$ in group $\mathrm{N}$ $(P=0.025)$.

\section{Conclusions}

Use of dexamethasone prior to subarachnoid block in patients undergoing total abdominal hysterectomy significantly reduces the incidence of nausea and vomiting and the requirement of antiemetic in the postoperative period, with better patient satisfaction.

\section{KEY WORDS}

Dexamethasone, gynaecological surgery, postoperative nausea and vomiting, subarachnoid block 


\section{INTRODUCTION}

Postoperative nausea and vomiting (PONV) is a common, troublesome and potentially hazardous complication of anaesthesia and surgery, with an estimated incidence as high as $70-80 \%$ in high risk patients. ${ }^{1,2}$ Though reported incidence of PONV with regional anaesthesia is lower compared to general anaesthesia, its deleterious effects to the individual patient is not different. ${ }^{3}$ Among various associated risk factors, gynaecological surgeries have also been identified as an independent risk factor for PONV. ${ }^{4}$

When severe, PONV is associated with wound dehiscence, bleeding, electrolyte imbalance, dehydration and pulmonary aspiration of gastric contents, resulting in prolonged hospital stay and increased health care cost. ${ }^{5}$ Therefore, the prevention and treatment of PONV has always remained an important responsibility of anaesthesia care provider.

Various prophylactic antiemetics have been used for the prevention and control of PONV. Dexamethasone has been shown to be effective prophylactic antiemetic with limited side effects during postoperative period. Further, it has been reported to have an additional advantage of reducing postoperative fatigue, pain and total analgesic requirement. $^{6}$

Although, plenty of literature is available on the use of dexamethasone as prophylactic antiemetic in major gynaecological surgeries under general anaesthesia, its use under spinal anaesthesia is limited. Therefore, the present study was designed primarily to find out the effects of dexamethasone as a prophylactic antiemetic in patients undergoing total abdominal hysterectomy under subarachnoid block. Influences of dexamethasone prophylaxis on patient satisfaction and postoperative analgesia were also observed and documented as secondary objectives.

\section{METHODS}

This was a prospective, randomized, double blind, placebo controlled study conducted in BPKIHS, a Tertiary care University based hospital from January 2009 to April 2009, for a period of four months. After obtaining institutional ethics committee approval and informed consent from all patients, this study was carried out in 80 American Society of Anaesthesiologist Physical Status I\&ll patients undergoing total abdominal hysterectomy (TAH) under subarachnoid block (SAB).

Patients receiving antiemetics and with history of hypersensitivity to steroid were excluded. All patients' age, weight, height, body mass index (BMI) and the prior history of motion sickness, vertigo, nausea and vomiting were noted. Patients were kept nil per orally for 8 hours before anaesthesia and were premedicated with tablet diazepam $10 \mathrm{mg}$ orally, the night before and 2 hours prior to surgery.
Patients were randomly allocated to receive $2 \mathrm{ml}$ of either $4 \mathrm{mg}$ dexamethasone (Group D) or normal saline (Group $\mathrm{N}$ ) intravenously, $1 \mathrm{hr}$ before $\mathrm{SAB}$ according to computer generated random order. The study medications were given by one of the investigators not involved in observing the outcome parameters.

All patients were preloaded with Ringers lactate $(10 \mathrm{ml} / \mathrm{kg})$. Heart rate, electrocardiogram, non-invasive blood pressure, pulse oximetry $\left(\mathrm{SpO}_{2}\right)$ were monitored throughout the surgery. All patients received continuous oxygen at $2 \mathrm{l} / \mathrm{min}$ using nasal prongs. Under all aseptic precautions, SAB was performed in lateral position using $25 \mathrm{G}$ Quenke's spinal needle, at $L_{3}-L_{4}$ interspace with $3.4 \mathrm{ml}$ of 0.5 percent hyperbaric bupivacaine. The level of sensory blockade achieved after 10 min of giving SAB was noted and the surgery was allowed to start only with a block height of T8 dermatome.

In the intraoperative period, hypotension ( $\mathrm{SBP}<20 \%$ of the preoperative value) was corrected with intravenous fluid and intravenous boluses of mephentermine $3 \mathrm{mg}$, bradycardia ( $\mathrm{HR}<60 / \mathrm{min}$ with hypotension or $<50 / \mathrm{min}$ without hypotension) was treated with intravenous bolus of atropine $0.3 \mathrm{mg}$ and nausea and vomiting was treated with bolus of ondansetron $4 \mathrm{mg}$, intravenously.

PONV was graded (0-no nausea and vomiting, one-nausea without vomiting, two-nausea with vomiting $<3$ episodes, three-nausea with vomiting $>3$ episodes) and documented every 4 hours till 24 hours after surgery. ${ }^{7}$ Any episode of PONV was treated with ondansetron four mg intravenously as a rescue antiemetic and was documented.

After the surgical procedure, when the level of sensory block receded to T10 level or patient complained of pain, whichever occurred first, intramuscular diclofenac sodium $75 \mathrm{mg}$ was given and was repeated 8 hourly up to $24 \mathrm{hrs}$ and then given orally thereafter. Supplemental analgesia for breakthrough pain was provided with slow intravenous tramadol $50 \mathrm{mg}$.

Postoperative pain was assessed using $10 \mathrm{~cm}$ visual analogue scale $(\mathrm{VAS})(0=$ no pain, $10=$ worst pain imaginable $)$, at the beginning of the demand of rescue analgesic and 30 min after giving the analgesic up to $24 \mathrm{hrs}$. The overall patients' satisfaction and the reasons for satisfaction or dissatisfaction were noted after $24 \mathrm{hrs}$.

The collected data was entered in Micro Soft Excel 2010 and then transferred it in to statistical package for social science (SPSS PC+17) for statistical analysis. Chi square test was used for qualitative variables and t-test for quantitative variables to find out the significant differences between the groups D and $\mathrm{N}$. The sample size (40 patients in each group) was estimated to detect a decrease in the incidence of nausea and vomiting from 50 percent to 20 percent with dexamethasone prophylaxis, with power of 80 percent and a confidence interval of 95 percent. $^{8}$ The P-value of less than 0.05 was considered statistically significant. 


\section{RESULTS}

Patient characteristics and the factors related to anaesthesia and surgery that may modify the incidence of PONV were similar between the two groups (table 1).

Intraoperative nausea and vomiting occurred in seven

Table 1.Patient characteristics and factors related to surgery and anaesthesia.

\begin{tabular}{|c|c|c|c|}
\hline Parameters & Group D $(n=40)$ & Group N (n=40) & $\begin{array}{l}p- \\
\text { value }\end{array}$ \\
\hline Age (yr) & $44 \pm 6$ & $45 \pm 9$ & 0.435 \\
\hline Weight (kg) & $52 \pm 9$ & $51 \pm 7$ & 0.577 \\
\hline Height (cm) & $152 \pm 8$ & $149 \pm 10$ & 0.213 \\
\hline $\mathrm{BMI}\left(\mathrm{kg} / \mathrm{m}^{2}\right)$ & $23.0 \pm 3.0$ & $23.0 \pm 3.3$ & 0.997 \\
\hline $\begin{array}{l}\text { No. of patients with } \\
\text { risk factors: history of } \\
\text { either motion sickness } \\
\text { or vertigo or nausea and } \\
\text { vomiting }(\%)\end{array}$ & $16(40 \%)$ & $15(37.5 \%)$ & 0.818 \\
\hline $\begin{array}{l}\text { Baseline heart rate } \\
\text { (beats/min) }\end{array}$ & $83 \pm 9$ & $82 \pm 13$ & 0.794 \\
\hline $\begin{array}{l}\text { Baseline mean BP ( } \mathrm{mm} \\
\mathrm{hg})\end{array}$ & $93 \pm 9$ & $94 \pm 11$ & 0.773 \\
\hline $\begin{array}{l}\text { No. of patients with } \\
\text { Sensory blockade level } \\
10 \text { min after SAB }\left(T_{4} /\right. \\
\left.T_{6} / T_{8}\right)\end{array}$ & $4 / 29 / 7$ & $3 / 26 / 11$ & 0.305 \\
\hline $\begin{array}{l}\text { No. of patients with } \\
\text { Intraoperative hypoten- } \\
\text { sion }(\%)\end{array}$ & $10(25 \%)$ & $14(35 \%)$ & 0.329 \\
\hline $\begin{array}{l}\text { Intraoperative fluid } \\
\text { used (I) }\end{array}$ & $3.3 \pm 1.6$ & $2.9 \pm 1.3$ & 0.265 \\
\hline Blood loss (ml) & $226 \pm 11$ & $238 \pm 95$ & 0.235 \\
\hline $\begin{array}{l}\text { Duration of Surgery } \\
\text { (min) }\end{array}$ & $87 \pm 23$ & $86 \pm 22$ & 0.922 \\
\hline
\end{tabular}

Table 2. Comparison of, incidence of different grades of postoperative nausea and vomiting. Values are expressed as number (\%).

\begin{tabular}{|lll|}
\hline PONV Grading & Group D & Group N \\
\hline 0 & $24(60 \%)$ & $13(32.5 \%)$ \\
\hline 1 & $11(27.5 \%)$ & $20(50 \%)$ \\
\hline 2 & $5(12.5 \%)$ & $3(7.5 \%)$ \\
\hline 3 & - & $4(10 \%)$ \\
\hline
\end{tabular}

Table 3. Comparison of incidence of PONV in patients with risk (with the history of motion sickness, vertigo, nausea and vomiting) and without risk. Values are expressed as number.

\begin{tabular}{|lll|}
\hline & Group D & Group N \\
\hline Patients with PONV / All patient & $16 / 40$ & $27 / 40$ \\
\hline $\begin{array}{l}\text { Patients with risk, developing PONV / patients } \\
\text { with risk }\end{array}$ & $8 / 16$ & $11 / 15$ \\
\hline $\begin{array}{l}\text { Patients without risk, developing PONV / } \\
\text { patients without risk }\end{array}$ & $8 / 24$ & $16 / 25$ \\
\hline
\end{tabular}

(17.5\%) and $11(27.5 \%)$ patients in Groups D and N

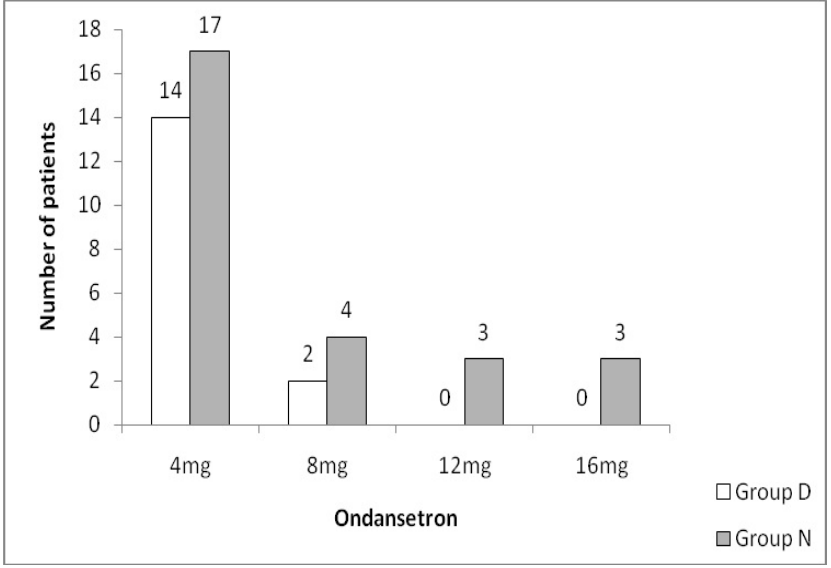

Figure 1. Requirement of rescue antiemetic in the postoperative period.

2a: Group D ( $n=26)$

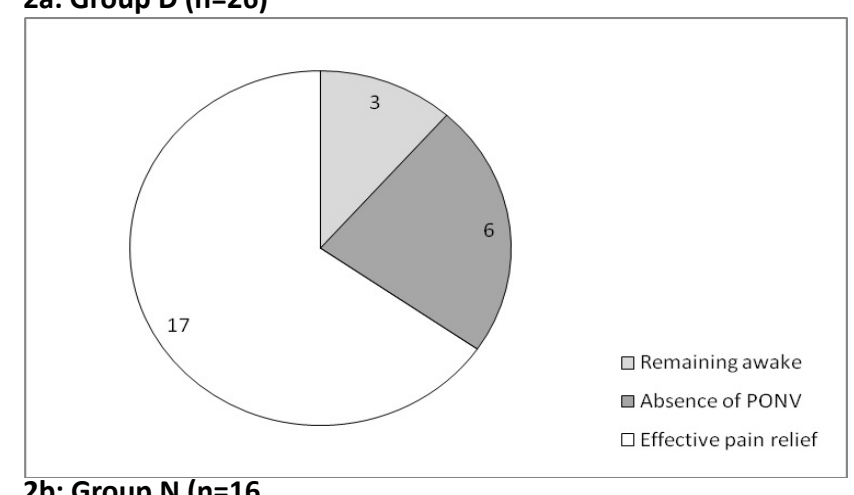

2b: Group N ( $n=16$

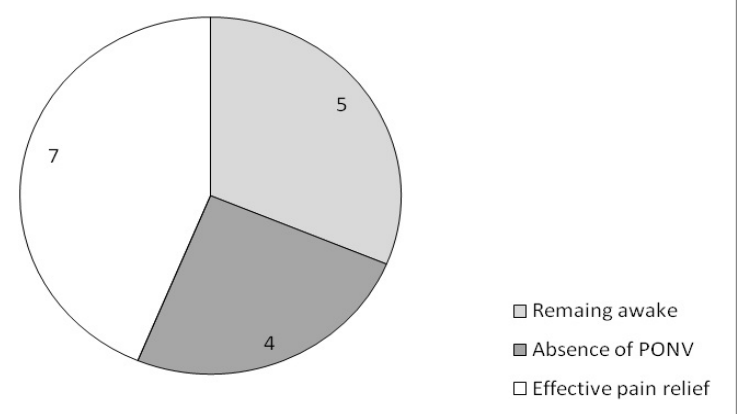

Figure 2. Frequency of satisfied patients and reasons for their satisfaction. Values are expressed as numbers.

respectively with no statistical difference $(P=0.284)$. In the postoperative period, significantly less number of patients i.e. 16 (40\%) in Group D experienced nausea and vomiting compared to $27(67.5 \%)$ in Group N (P=0.013) (table2). Further, the mean requirement of rescue antiemetic in patients developing postoperative nausea and vomiting was significantly less in patients of Group D than in Group N (4.5 $\pm 1.3 \mathrm{mg}$ vs. $6.8 \pm 4.2 \mathrm{mg}, \mathrm{P}=0.042$ ) (fig 1 ). Nineteen (61\%) of 31 , high risk patients developed nausea and vomiting in the postoperative period (table-3). Twenty-three (57.5\%) patients in Group N and only 15 (37.5\%) patients in Group $D$ required rescue analgesic in the postoperative period ( $P$ $=0.058)$.

After 24 hrs of surgery, $26(65 \%)$ patients in group D expressed overall satisfaction compared to only 16 (40.0\%) in group $N(P=0.025)$ (fig 2). Of the 14 unsatisfied patients 
in group D, eight $(57.1 \%)$ patients expressed PONV and six (42.9\%) inadequate pain relief as the reasons for their dissatisfaction. In group N, 16 (69.6\%) and eight (30.4\%) patients expressed PONV and inadequate pain relief respectively as the reasons for their dissatisfaction ( $P$ $=0.079$ ).

\section{DISCUSSION}

Dexamethasone has been shown to be an effective antiemetic in patients receiving cancer chemotherapy. ${ }^{9-11}$ Though, few investigations have failed to demonstrate postoperative antiemetic and analgesic affects, several studies have shown that dexamethasone effectively decreases the incidence of PONV, and provides

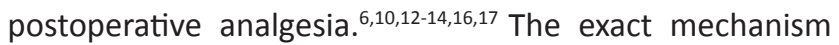
of dexamethasone induced antiemetic and analgesic effects still remains to be fully understood. However, it has been postulated to be related to inhibition in the synthesis of prostaglandins, associated with triggering of emesis and inflammatory response. ${ }^{18}$ Antagonism of 5HTreceptors in the central nervous system is another possible mechanism of antiemetic effects of dexamethasone. ${ }^{9}$ Finding out whether there are any specific mechanisms of antiemetic effect of dexamethasone in PONV associated with central neuraxial block could be an interesting topic of investigation.

Various doses of dexamethasone ranging from $1.25-25 \mathrm{mg}$ have been used for reducing PONV with varying success. ${ }^{13,19}$ Since a dose of 2.5 or $5 \mathrm{mg}$ were found to be equally effective as $10 \mathrm{mg}$ in reducing the incidence of postoperative emesis in patients undergoing major gynaecological surgeries, a dose of $4 \mathrm{mg}$ was chosen in this study. ${ }^{13}$

Our study has shown that prophylactic use of $4 \mathrm{mg}$ dexamethasone intravenously 1 hour prior to $\mathrm{SAB}$, in patients undergoing $\mathrm{TAH}$, significantly reduces the incidence of nausea and vomiting and the requirement of antiemetics in the postoperative period.

The incidence of intraoperative nausea and vomiting were not significantly different between the two groups in our study. This finding is quite expected as we had administered dexamethasone 1 hour prior to $S A B$ and the onset of antiemetic effect of prophylactic dexamethasone is approximately 2 hours. ${ }^{20}$

Our study showed almost $28 \%$ reductions in the incidence of PONV with the use of dexamethasone. This finding is similar to the findings by Gautam et al and Tjeng et al who showed $23.4 \%$ and $32 \%$ decrease in the incidence of PONV respectively with the use of prophylactic dexamethasone although there were number of differences for comparison between our and their studies in terms of types of surgery, anesthetic technique employed, analgesic used and the overall study design itself. 21,22

Significant reduction in the need of rescue antiemetic in dexamethasone group in our study in consistence with previous studies, further confirms its antiemetic effect. ${ }^{13,20,23}$ Thus, our finding shows effective prevention of PONV associated with central neuraxial blockade with the use of prophylactic dexamethasone.

Various reasons have been mentioned for PONV in patients undergoing surgeries under central neuraxial block including hypotension, hyper peristalsis, traction on nerve endings and plexus, hypoxemia etc. ${ }^{24}$ The etiology of PONV after gynaecological surgery is multifactorial. A number of factors, including age, obesity, history of motion sickness or previous PONV, menstrual cycle, surgical procedure and postoperative pain, are considered to increase the incidence of PONV. ${ }^{25,26}$

One can note that the incidence of PONV following SAB in our study is higher in both the intervention and control groups than that in the reported literature..$^{8,13,16}$ We attribute this to the major gynaecological surgery and female sex that we chose in our study as both are considered as significant risk factors for PONV in themselves. ${ }^{3,4}$ Presence of significant proportion of high risk patients (i.e. with the history of motion sickness, vertigo, nausea and vomiting) as well as the use of tramadol as a rescue analgesic could have further contributed to the higher incidence of PONV in our study. ${ }^{2}$

As reported by BisGaard T et al, we also observed decreased analgesic requirement in patients receiving dexamethasone almost becoming statistically significant. ${ }^{6}$ Reduction in pain, analgesic requirement and duration of convalescence substantiated by reduction in the inflammatory marker C-reactive protein has been reported with the use of dexamethasone. ${ }^{6}$

In our study, we observed better overall patient satisfaction with the use of prophylactic dexamethasone. Interestingly, nausea and vomiting was reported by most of the subjects who were not satisfied as the major reason for their dissatisfaction.

The use of tramadol as a rescue analgesic in the postoperative period was the main limitation of our study.

\section{CONCLUSION}

We conclude that prophylactic use of dexamethasone prior to $\mathrm{SAB}$ in patients undergoing TAH significantly reduces the incidence of nausea and vomiting and the requirement of antiemetic in the postoperative period, with better patient satisfaction. Hence in the absence of specific contraindications, we recommend routine use of dexamethasone in patients undergoing TAH under SAB. 


\section{REFERENCES}

1. Woodhouse A, Mather LE. The effect of duration of dose delivery with patient - controlled analgesia on the incidence of nausea and vomiting after hysterectomy. Br J clin pharmacol 1998; 45: 57-62.

2. Apfel CC, Laara E, Koivuranta M. A simplified risk scores for predicting postoperative nausea and vomiting: conclusions from crossvalidations between two centers. Anesthesiology 1999; 91: 693-700.

3. Islam S, Jain PN. Postoperative nausea and vomiting: A review article. Indian J. Anaesth 2004; 48:253-258.

4. Kenny GNC. Risk factors for postoperative nausea and vomiting. Anaesthesia 1994; 49: 6-10.

5. Ramanathan, Augustus, Thiruvengadam, Sundaram M, Deepalakshmi. Efficacy of propofol in preventing postoperative nausea and vomiting: single blind randomized control study. The Internet Journal of Anaesthesiology 2003; 7:1092-406.

6. Bisgaard T, Klarskov B, Kehlet H, Rosenberg J. Preoperative dexamethasone improves surgical outcome after laparoscopic cholecystectomy: A randomized double blind placebo- controlled trial. Ann Surg 2003; 238: 651-60.

7. Kontrimaviciute E, Baublys A, Ivaskevicius J. Postoperative nausea and vomiting in patients undergoing total abdominal hysterectomy under spinal anaesthesia: a randomized study of ondansetron prophylaxis. Eur J Anaesthesiol 2005; 22: 504-9.

8. Callesen T, Schouenborg L, Nielsen D, Guldager $H$, Kehlet $H$. Combined epidural-spinal opioid-free anaesthesia and analgesia for hysterectomy. Br J Anaesth 1999; 82: 881-5

9. Grunberg SM. Antiemetic activity of corticosteroids in patients receiving cancer chemotherapy: dosing, efficacy, and tolerability analysis. Ann Oncol 2007; 18: 233-240.

10. Jones AL, Hill AS, Soukop M, Hutcheon AW, Cassidy J, Kaye SB, et.al. Comparison of dexamethasone and ondansetron in the prophylaxis of emesis induced by moderately emetogenic chemotherapy. Lancet 1991; 338: 483-7.

11. Tavorath R, Hesketh PJ. Drug treatment of chemotherapy induced delayed emesis. Drugs 1996; 52; 639-48.

12. Tan PH, Liu K, Peng CH, Yang LC, Lin CR, Lu CY. The effect of dexamethasone on postoperative pain and emesis after intrathecal neostigmine. Anesth Analg 2001; 92: 228-32.

13. Liu K, Hsu CC, Chia YY. The effective dose of dexamethasone for antiemesis after major gynaecological surgery. Anesth Analg 1999; 89: 1316-8.

14. Wu JI, Lo Y, Chia YY, Liu K, Fong WP, Yang LC. Prevention of postoperative nausea and vomiting after intrathecal morphine for cesarean section; a randomized comparison of dexamethasone, droperidol, and a combination. International Journal of Obstetric Anesthesia 2007; 16: $122-127$
15. Fujii $Y$, Tanaka $H$, Toyooka $H$. The effects of dexamethasone on antiemetics in female patients undergoing gynaecologic surgery. Anesth Analg 1997; 85: 913-7.

16. Jaafarpour M, Khani A, Dyrek vandmoghadam A, Khajavikhan J, Saadipour Kh. The effect of dexamethasone on nausea, vomiting and pain in parturents undergoing caesarean delivery. Journal of Clinical and Diagnostic Research 2008; 3: 854-858.

17. Movafegh A, Soroush AR, Navi A, Sadeghi M, Esfehani F, Tefaghi $\mathrm{N}$. The effect of intravenous administration of dexamethasone on postoperative pain, nausea, and vomiting after intrathecal injection of meperidine. Anesth Analg 2007; 104: 987-9.

18. Apro MS, Plezia PM, Alberts DS, Graham V, Jones SE, Surwit EA, et.al. Double-blind cross-over study of the antiemetic efficacy of high-dose dexamethasone versus high dose metoclopramide. J Clin Oncol 1984; 2: 466-71.

19. Subramaniam B, Madan R, Sadhasivam S, Sennaraj B, Tamilselvan P, Rajeshwari $S$, et. al. Dexamethasone is a cost-effective alternative to ondansetron in preventing PONV after paediatric strabismus repair. Br J Anaesth 2001; 86:84-9

20. Wang JJ, Ho ST, Tzeng JI, and Tang CS. The effect of timing of dexamethasone administration on its efficacy as a prophylactic antiemetic for postoperative nausea and vomiting. Anesth Analg 2000; 91: $136-139$

21. Gautam B, Shrestha BR, Lama P, Rai S. Antiemetic prophylaxis against postoperative nausea and vomiting with ondansetron - dexamethasone combination compared to ondansetron or dexamethasone alone for patients undergoing laparoscopic cholecystectomy. Kathmandu Univ Med J (KUMJ) 2008; 6: 319-328.

22. Tzeng Jl, Hsing $\mathrm{CH}$, Chu CC, Chen $\mathrm{YH}$, Wang JJ. Low dose dexamethasone reduces nausea and vomiting after epidural morphine: A comparison of metoclopramide with saline. J Clin Anaesth 2002; 14:19-23.

23. Olando L, Carrascosa F, Pueyo FJ, Monedero P, Busto N, Saez A. Combination of ondansetron and dexamethasone in the prophylaxis of postoperative nausea and vomiting. B J Anaesth 1996; 76: 835-40.

24. Mc Leod G. spinal anesthesia - intradural and extradural. In: Davies NJH, Cashman JN (Eds). Lee's Synopsis of Anaesthesia 13th ed. Elsevier Singapore, 2006: 514-515.

25. Apfel CC, Greem CA, Haubitz I, Grundt D, Goepfert C, Sefrin P, et. al. The discriminating power of a risk score for postoperating vomiting in adults undergoing various types of surgery. Acta Anaesthesiol Scand 1998; 42:502-9.

26. Sinclair DR, Chung F, Mezei G. Can postoperative nausea and vomiting be predicted? Anesthesiology 1998; 91:109-18. 